\title{
ANALYSIS OF CHANGE OF THE COLOUR PARAMETERS OF PAPRIKA POWDER WITH DIFFERENT ADDED OLEORESIN Zsuzsanna H. Horváth
}

Faculty of Engineering,

University of Szeged, H-6724 Szeged, Mars tér 7., Hungary

e-mail: horvatzs@mk.u-szeged.hu

\begin{abstract}
The instrumental colour measurement isn't used in course of the making and the qualification of the paprika powder, although the colour is the most important sense property of its. Paprika is also used as a natural food colour. The colour of paprika powder is very important too, because the consumer concludes its colouring power based on its colour. The colouring power is determined by quality and quantity of colouring agent of paprika squarely. The colour of the powder is influenced by its particle size, oil content and moisture content and first of all the colour agent content.

We investigated how the colour agent content increasing influences the colour characteristics of paprika powders. The $\mathrm{L}^{*}, \mathrm{a}^{*}, \mathrm{~b}^{*}$ colour coordinates defined in the CIELab colour space were applied for the colour characterization. The measurements were carried out using a Minolta CR300 tristimulus colour analyser.

We loosed the colour agent from the paprika powder samples using acetone. The colour agent content of obtained samples was less than 10 ASTA units. After different quantity of oleoresin ( $0.0186 \mathrm{~g}, 0.0461 \mathrm{~g}, 0.0626 \mathrm{~g}, 0.0953,0.3500 \mathrm{~g}, 0.6399 \mathrm{~g}$ ) was added to samples of $10 \mathrm{~g}$ of powder. The colour characteristics and colour agent content of these samples were determined. The relation between colour agent content and colour coordinates was analysed using regression analysis and the colour differences $\Delta \mathrm{E}_{\mathrm{ab}}^{*}$ were determined between samples with different colour agent content.

The results depicted that $\mathrm{L}^{*}$ lightness coordinate decreased with increasing colour agent content, the points fitted on a reciprocal function with a significant correlation ( $p=0.01)$. In the case of $\mathrm{a}^{*}$ redness coordinate the points fitted on a saturation function $(0.01)$, the redness coordinate didn't change above 129 ASTA units. The $b^{*}$ yellowness coordinate increased to 97 ASTA units, then decreased, the points fitted on a second degree function with a significant correlation ( $\mathrm{p}=0.01)$. The function has maximum at 97.17 ASTA units; the maximum value was 25.22 coordinate units. The value of hue angle $\left(h_{a b}^{o}\right)$ progressively decreased while the colour agent content was added. The $\mathrm{C}_{\mathrm{ab}}^{*}$ chroma increased to 121 ASTA units, then decreased, the points fitted on a second degree function with a significant correlation $(\mathrm{p}=0.01)$. It depicts, that the colour of powder became more red and darker as the colour agent content increased. The colour differences $\Delta \mathrm{E}_{\mathrm{ab}}^{*}$ calculated between samples with different colour agent content were smaller above 130 ASTA units. It shows that the rate of the change of the paprika powders colour was smaller while the colour agent content increased.
\end{abstract}

\section{INTRODUCTION}

The use of natural food colours is preferred to that of artificial dyestuffs for modern alimentary purposes. Paprika is a spice plant grown and consumed in considerable quantities worldwide and also used as a natural food colour. Hungarian paprika powder is still regarded as a "Hungaricum" today. Paprika is cultivated in areas of the world such as Spain, South Africa and South America, where the weather is favourable for the growth of this plant and for the development of its red colouring agents. The large number of hours of sunshine allows the paprika to ripen on its stock, so that the basic material reaching the processing mills has high dyestuff content. Hungarian paprika has a unique aroma and a specific smell, but the production of powder with a good red colour is a considerable problem. The colour of paprika powder is very important, 
because the consumer concludes its colouring power based on its colour, although the relation isn't unequivocal between them (H.Horváth, 2005). The colouring power is determined by quality and quantity of colouring agent of paprika squarely, but the colour of the powder is influenced by many factors besides the colouring agent content. Various investigations have been made of the connection between the colouring agent content of the powder and the colour characteristics measured by different techniques (Navarro et al., 1993, Nieto- Sandoval et al., 1999). Such investigations have yielded partial results, but there is no formula that describes the correlation between the colouring agent content and the colour characteristics. Since the 1970s a number of papers have been published on measurements of the colour of paprika powders (Horváth\&Kaffka, 1973, Drdak et al., 1980, Huszka et al., 1984, Drdak et al., 1989). Measurements have been performed relating to the changes in the colour stimulus components $\mathrm{X}, \mathrm{Y}$ and $\mathrm{Z}$ of powders during mixing (Huszka et al., 1984) and to the correlation between visual sensing and the instrumentally measured colour characteristics (Huszka et al., 1985). The effects of ionizing irradiation on the colour of paprika powder were investigated by Fekete-Halász et al. (1996). Minguez et al. (1997) analysed how the colour of the powder is changed by the ratio of the yellow and red pigments within the total colouring agent content. Chen et al. (1999) investigated the effects of particle size in Korean cultivars and established that the lightness coordinate of the powder was influenced by the particle size. Applying a Hungarian milling technique, Horváth\&Halász-Fekete (2005) demonstrated that the particle size exerts a significant influence on all three colouring characteristics of powders made from Hungarian, South African and South American paprika. Kispéter et al. (2003) investigated the influence exerted on the colour by saturated steam used for germ reduction. In the case of Korean cultivars, no significant change in colour characteristics was detected when the moisture content varied between $10 \%$ and $15 \%$ (Chen et al., 1999). H.Horváth\&Hodúr (2007a) investigated Hungarian paprika powders and depicted, that the colour of the powder was observed to turn into darker and deeper red with increasing moisture content.

The influence of physical and chemical properties of paprika powder on its color was investigated in course of our work. In this paper is presented, how the color characteristics of paprika powders change following increase of color agent content.

\section{METHODS AND MATERIALS}

\subsection{Color measurement}

Color measurements were performed with a Minolta CR-300 tristimulus color measuring instrument. The CIELab color system was used for colour characterization. In this color space the colour points are characterized by three color coordinates. $L^{*}$ is the lightness coordinate ranging from no reflection for black $\left(L^{*}=0\right)$ to perfect diffuse reflection for white $\left(L^{*}=100\right)$. The $a^{*}$ is the redness coordinate ranging from negative values for green to positive values for red. The $b^{*}$ is the yellowness coordinate ranging from negative values for blue and positive values for yellow.

The total colour change is given by the colour difference $\left(\Delta E_{a b}^{*}\right)$, in terms of the spatial distance between two colour points interpreted in the colour space: (Hunter, 1987)

$$
\Delta E_{a b}^{*}=\left[\left(L_{1}^{*}-L_{2}^{*}\right)^{2}+\left(a_{1}^{*}-a_{2}^{*}\right)^{2}+\left(b_{1}^{*}-b_{2}^{*}\right)\right]^{1 / 2} .
$$

If $1.5<\Delta E_{a b}^{*}<3$, then the color difference between two paprika grists can hardly be visually distinguished, if $\Delta E_{a b}^{*}>3$, then the color difference between two paprika grists can be visually distinguished (H.Horváth, 2007b). 
The chroma $\left(C_{a b}^{*}\right)$ was used to determine the change of color.

$$
C_{a b}^{*}=\left(\left(a^{*}\right)^{2}+\left(b^{*}\right)^{2}\right)^{\frac{1}{2}}
$$

The chroma represents color saturation which varies dull at low chroma values to vivid color at high chroma values (Hunter, 1987).

The shade of color point was characterised by CIELab $h_{a b}^{0}$ hue angle.

$$
\mathrm{h}_{\mathrm{ab}}^{\mathrm{o}}=\operatorname{arctg}\left(\frac{\mathrm{b}^{*}}{\mathrm{a}^{*}}\right)
$$

\subsection{Preparation and measurement of the samples with increased color agent content}

First the colour agent was loosed from the paprika powder samples using acetone. The colour agent content of obtained samples was less than 10 ASTA units. After different quantity of oleoresin ( 0.0186g, 0.0461g, 0.0626g, 0.0953, 0.3500g, $0.6399 \mathrm{~g}$ ) was added to samples of $10 \mathrm{~g}$ of powder. After the color coordinates of these samples were measured in 3 parallel measurements and colour agent content of these samples were determined too.

The relationship between colour agent content and colour coordinates was analysed using regression analysis and the colour differences $\Delta \mathrm{E}_{\mathrm{ab}}^{*}$ were calculated between samples with different colour agent content.

\section{RESULTS AND DISCUSSION}

Table 1 presents the colour agent content, the lightness coordinate, the redness coordinate, the yellowness coordinate, the hue angle and chroma values of paprika powder samples with different quantity added oleoresin.

Table 1. The color agent content and color parameters of different samples

\begin{tabular}{|r|r|r|r|r|r|r|}
\hline $\begin{array}{c}\text { Quantity of } \\
\text { added } \\
\text { oleoresin } \\
\text { (g) }\end{array}$ & $\begin{array}{c}\text { Color agent } \\
\text { content } \\
\text { (ASTA) }\end{array}$ & \multicolumn{1}{c|}{$\mathbf{L}^{*}$} & \multicolumn{1}{|c|}{$\mathbf{a}^{*}$} & \multicolumn{1}{c|}{$\mathbf{b}^{*}$} & \multicolumn{1}{c|}{$\mathbf{h}_{\mathrm{ab}}^{\mathbf{0}}$} & \multicolumn{1}{c|}{$\mathbf{C}_{\mathbf{a b}}^{*}$} \\
\hline 0.0000 & 2 & 49.31 & 5.45 & 21.30 & 75.65 & 21.98 \\
\hline 0.0186 & 21 & 45.88 & 9.36 & 23.96 & 68.66 & 25.72 \\
\hline 0.0461 & 38 & 44.01 & 12.24 & 25.38 & 64.25 & 28.17 \\
\hline 0.0626 & 88 & 40.25 & 16.36 & 25.08 & 56.89 & 29.95 \\
\hline 0.0953 & 129 & 37.50 & 18.40 & 23.32 & 51.72 & 29.71 \\
\hline 0.3500 & 173 & 36.00 & 18.67 & 21.50 & 49.03 & 28.47 \\
\hline 0.6399 & 218 & 34.27 & 18.51 & 19.12 & 45.93 & 26.61 \\
\hline
\end{tabular}

Figures 1 demonstrates the relationships between the $L^{*}, a^{*} b^{*}$ colour coordinates and the colour agent content. The color coordinates are presented function of color agent content. The regression function and the determination coefficients are given. 


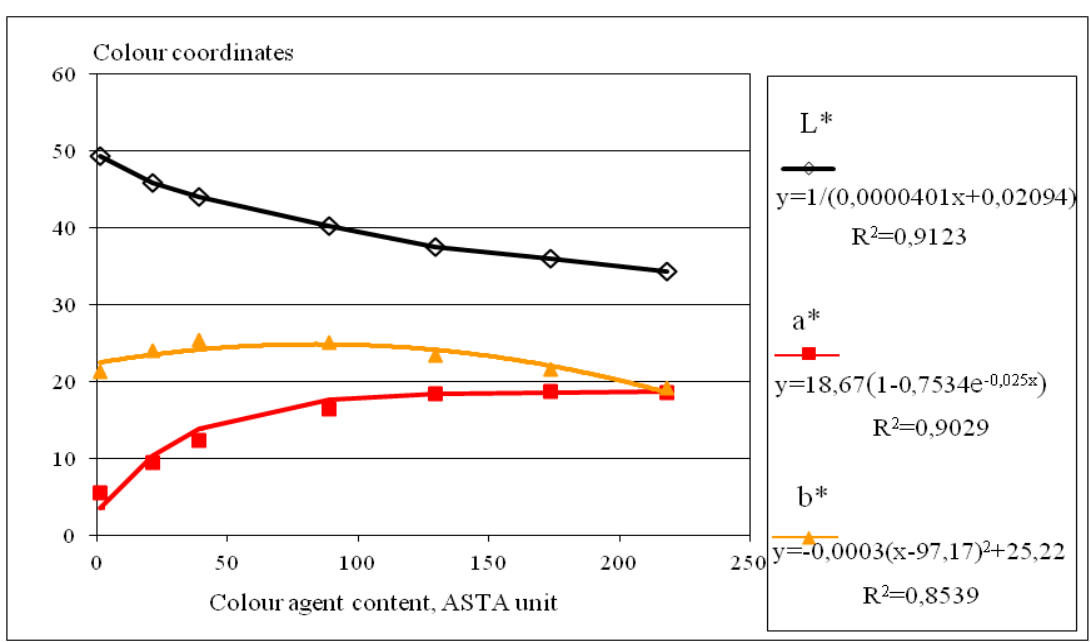

Fig. 1. Relationship between the $L^{*}, a^{*} b^{*}$ colour coordinates and the colour agent content

The results depict that $\mathrm{L}^{*}$ lightness coordinate decreased with increasing colour agent content, the points fitted on a reciprocal function with a significant correlation $(p=0.01)$. In the case of $a^{*}$ redness coordinate the points fitted on a saturation function (0.01), the redness coordinate didn't change above 129 ASTA units. The $b^{*}$ yellowness coordinate increased to 97 ASTA units, then decreased, the points fitted on a second degree function with a significant correlation ( $\mathrm{p}=0.01$ ). The function has maximum at 97.17 ASTA units; the maximum value was 25.22 coordinate units. Figures 2 presents relationship between the hue angle $\left(\boldsymbol{h}_{a b}^{0}\right)$ AND the colour agent content, and relationship between the chroma $\left(\boldsymbol{C}_{a b}^{*}\right)$ and the colour agent content. The hue angle and chroma are presented function of color agent content. The regression function and the determination coefficients are given.

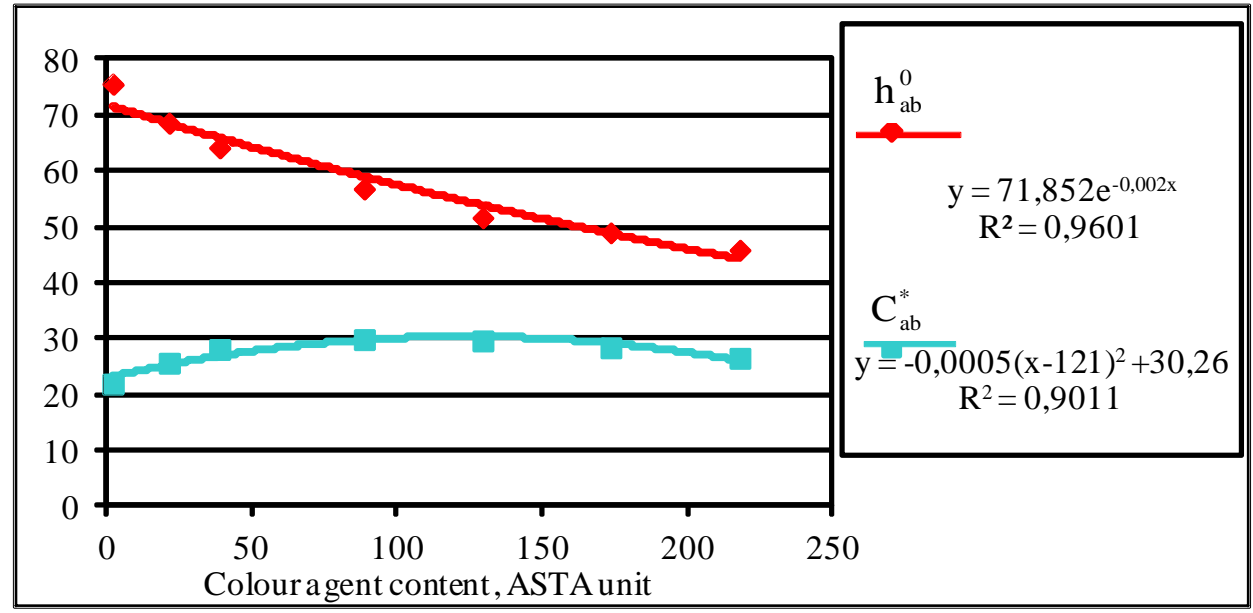

Fig. 2. Relationship between the hue angle $\left(\boldsymbol{h}_{a b}^{0}\right)$ AND the colour agent content, and relationship between the chroma $\left(C_{a b}^{*}\right)$ and the colour agent content

The value of hue angle $\left(h_{\mathrm{ab}}^{0}\right)$ progressively decreased while the colour agent content was added. The $\mathrm{C}_{\mathrm{ab}}^{*}$ chroma increased to 121 ASTA units, then decreased, the points fitted on a second degree function with a significant correlation $(\mathrm{p}=0.01)$. It depicts, that the colour of powder became more red and darker as the colour agent content increased. Figure 3 
presents the colour differences $\Delta \mathrm{E}_{\mathrm{ab}}^{*}$ calculated between samples with different colour agent content.

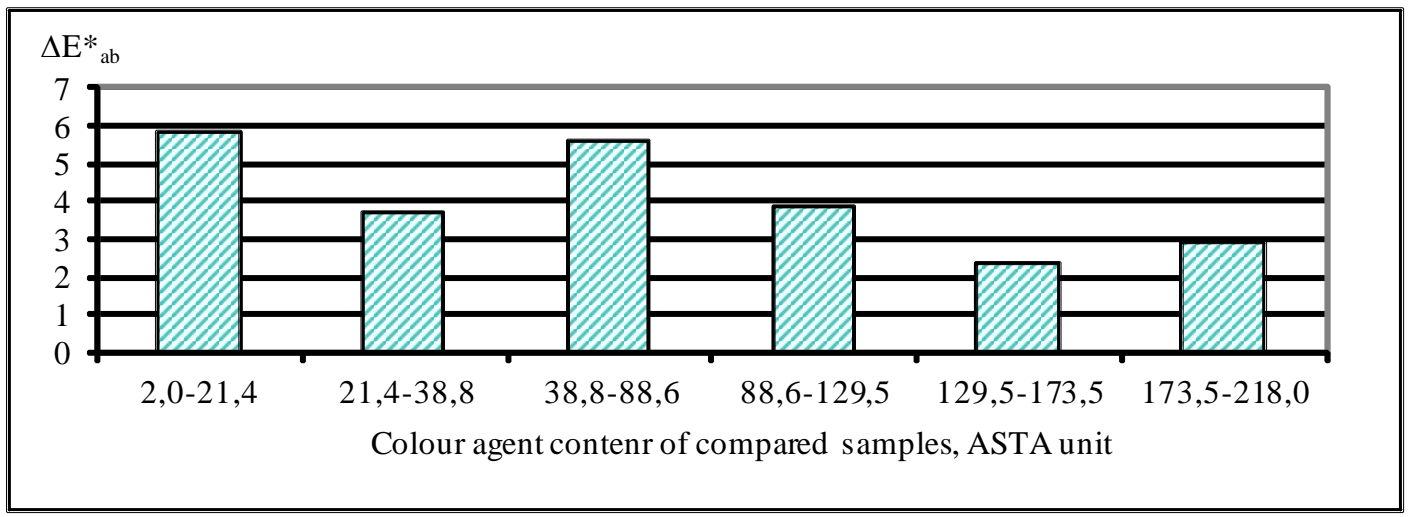

Fig. 3. Value of colour differences $\Delta E_{a b}^{*}$ calculated between samples with different colour agent content

It shows that the colour differences $\Delta \mathrm{E}_{\mathrm{ab}}^{*}$ calculated between samples with different colour agent content were smaller above 130 ASTA units. It shows that the rate of the change of the paprika powders colour was smaller while the colour agent content increased. The colour difference between samples was definitely perceptible under 130 ASTA units.

\section{CONCLUSION}

- The L* lightness coordinate decreased with increasing colour agent content.

- The $b^{*}$ yellowness coordinate increased to 97 ASTA units, then decreased.

- The value of hue angle $\left(\mathrm{h}_{\mathrm{ab}}^{\circ}\right.$ ) progressively decreased while the colour agent content was added.

- The $\mathrm{C}_{\mathrm{ab}}^{*}$ chroma increased to 121 ASTA units, then decreased.

- The colour of powder became more red and darker as the colour agent content increased.

\section{REFERENCES}

1. Chen Q., Hak-kyun-koh., Jae-Bok-Park., (1999): Color evalution of red pepper powder. Transaction-of-the-ASAE,. 42(3), 749-752.

2. Bok-Park (1999): Color evalution of red pepper powder. Transaction-of-theASAE. 42(3), 749-752.

3. Drdak M., Sorman L., Zemkova M., Schaller A., (1980): Ergebnisse von Studien über denZusammenhang zwischen Zusammensetzung und Farbe von gemahlenem Gewürrzpaprika. Confructa, 25(3/4), 141-146.

4. Drdak M., Greif G., Kusy P., (1989): Comparasion between the sensory and spectrophotometric method for determination of colour of paprika powder. Nahrung 33(8), 737-742.

5. Fekete-Halász M., Kispéter J., (1996): Effect of irradiation on colour of ground red paprika. Acta Alimentaria 25(2), 189-193.

6. H.Horváth, Zs., Halász-Fekete M., (2005): Instrumental colour measurement of paprika grist,. Annals of the Faculty of Engineering Hunedora, 101-107.

7. Zs., H.Horváth, C. Hodúr (2007a): The colour of paprika powders with different moisture content. International Agrophysics, 21: 67-72 p. 
8. Zs., H.Horváth (2007b): Procedure for setting the colour characteristics of paprika grist mixtures. Acta Alimentaria, 36: 75-88. p

9. Horváth L., Kaffka K., (1973): Instrumental Colorimetry of Red-pepperGrist. Mérés és Automatika 21(9) 341-348. (In Hungarian)

10. Hunter R., 1987. The measurement of appearance. Wiley Press, New York

11. Huszka T., Halászné Fekete M., Horváth M. Zs., Lukács Gy., (1984): Számítógépes színrecept számítási eljárás füszerpaprika őrlemények optimalizált előállítására. Mérés és Automatika, 32(5) 170-177.(In Hungarian)

12. Huszka T., Halász-Fekete M., Lukács Gy., (1985): Colour Tolerance of RedPepper Powders. Hungarian Scientific Instruments 60, 43-47.

13. Huszka, T., Horváth, Zs., Halász-Fekete, M., Véha, A., Gyimes, E., (1990): Computer aided quality planning and production control of red-pepper powders. $4^{\text {th }}$ European Seminar of the EOQ Food Section, Berlin, Procedings, 176-178.

14. Kispéter J., Bajúsz-Kabók K., Fekete M., Szabó G., Fodor G., Páli T., (2003): Changes induced in spice paprika powder by treatment with ionizing radiation and saturated stream. Radiation Physics and Chemistry 68, 893-900.

15. Minguez-Mosquera M. I., Perez-Galvez A. (1997): Color quality in paprika oleoresins. Journal of Agricultural and Food Chemistry 46 (12), 5124-5127.

16. Navarro F., Costa J., (1993): Evalution of Paprika Pepper Color by Tristimulus Colorimerty. Revista Espanola de Ciencia y Tecnologia de Alimentos 33(4):427434.

17. Nieto-Sandoval J. M., Fernandez-Lopez J. A., Almela L., Munoz J. A., (1999): Dependence betwen apparent color and extractable color in paprika. Color Research and Application 24(2), 93-97. 